\title{
X-linked intellectual disability-corpus callosum agenesis-spastic quadriparesis syndrome
}

INSERM

\section{Source}

INSERM. (1999). Orphanet: an online rare disease and orphan drug data base. $\underline{X \text {-linked }}$ intellectual disability-corpus callosum agenesis-spastic quadriparesis syndrome.

ORPHA:85330

X-linked intellectual disability-corpus callosum agenesis-spastic quadriparesis syndrome is characterised by intellectual and motor deficit, spastic quadriparesis and agenesis of the corpus callosum, without craniofacial abnormalities or seizures. It has been described in four male members of a family. The mode of inheritance is most likely X-linked recessive. 